\title{
Assessing altimetry close to the coast
}

\author{
G.D. Quartly, F. Nencioli, D. Conley, \& S. Abdalla
}

\section{Citation:}

Quartly, G.D., F. Nencioli, D. Conley, and S. Abdalla, "Assessing altimetry close to the coast", in Remote Sensing of the Ocean, Sea Ice, Coastal Waters, and Large Water Regions, edited by C.R. Bostater, Jr., S.P. Mertikas, X. Neyt, and S. Babichenko, Proc. of SPIE Vol. 10422, 104220T (2017)

\section{Copyright Notice:}

Copyright 2017 Society of Photo-Optical Instrumentation Engineers. One print or electronic copy may be made for personal use only. Systematic reproduction and distribution, duplication of any material in this paper for a fee or for commercial purposes, or modification of the content of the paper are prohibited. 


\section{Assessing altimetry close to the coast}

G. D. Quartly, F. Nencioli, D. Conley, S. Abdalla 


\title{
Assessing altimetry close to the coast
}

\author{
G.D. Quartly*a, F. Nencioli ${ }^{\mathrm{a}}$, D. Conley ${ }^{\mathrm{b}}$, S. Abdalla ${ }^{\mathrm{c}}$ \\ ${ }^{a}$ Plymouth Marine Laboratory, Plymouth, UK; ${ }^{b}$ University of Plymouth, Plymouth, UK; \\ ${ }^{c}$ ECMWF, Reading, UK,
}

\begin{abstract}
Radar altimetry provides measurements of sea surface elevation, wind speed and wave height, which are used operationally by many agencies and businesses, as well as for scientific research to understand the changes in the oceanatmosphere interface. For the data to be trustworthy they need to be assessed for consistency, and for bias relative to various validation datasets. Sentinel-3A, launched in Feb. 2016, promises, through new technology, to be better able to retrieve useful measurements in the coastal zone; the purpose of this paper is develop ideas on how the performance of this instrument can be assessed in that specific environment. We investigate the magnitude of short-term variability in wave height and range, and explain how two validation facilities in the southwest UK may be used.
\end{abstract}

Keywords: coastal altimetry, significant wave height, Sentinel-3A, validation

\section{INTRODUCTION}

Radar altimetry is a long-established technique for measuring many properties of the ocean surface, chief of which are the sea level, the significant wave height $\left(\mathrm{SWH}\right.$ or $\left.\mathrm{H}_{\mathrm{s}}\right)$ and the small-scale roughness, which is used to infer the wind speed at $10 \mathrm{~m}$ above the surface. All this information is derived from the position and shape of the echoes of the radar pulses from the surface (see Fig. 1a); however in coastal areas the underlying assumption of a homogeneous reflecting surface within the footprint may fail due to sharper changes in wind or wave conditions ${ }^{1}$, or due to the extra reflections obtained from land preceding the marine signal. Thus, unfortunately, altimetry accuracy is generally reduced in the coastal region $^{2}$, which is where its data would have the greatest societal impact, through monitoring of storm surges or of enhanced wave conditions battering shoreline structures.
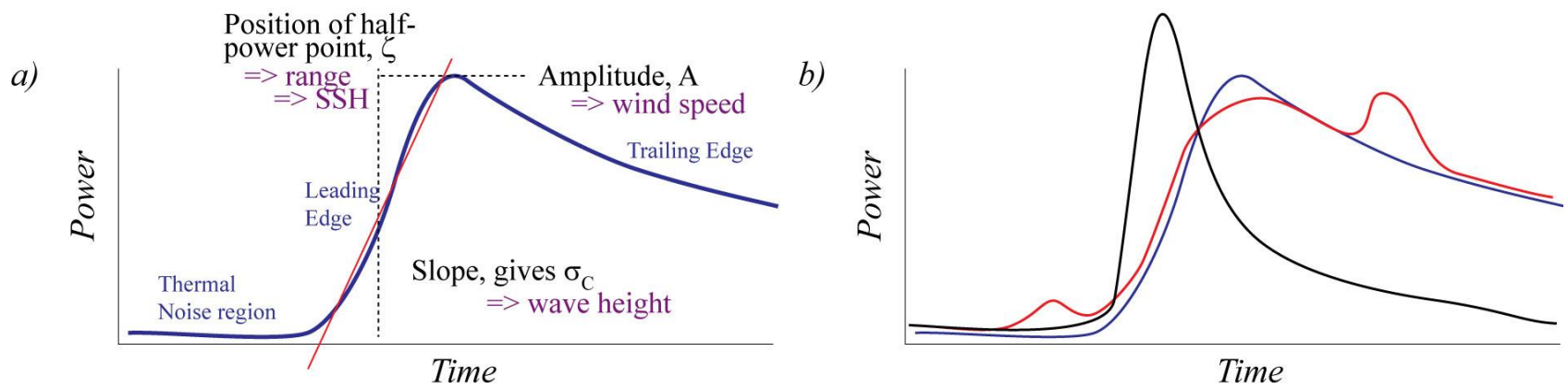

Figure 1. Radar altimeter echoes ('waveforms') and their interpretation. a) Schematic of waveform shape for a conventional LRM altimeter over a homogeneous surface showing how the three key geophysical parameters are linked to the shape. b) Contrast of pure ocean signal (blue), with one contaminated by extra signals from land (red). Also shown is the sharper waveform achieved by SAR processing (black). All schematic waveforms are free from Rayleigh (fading) noise, which for real data adds significant variability in the power at neighbouring points along the abscissa.

For the echo waveforms from conventional low rate mode (LRM) altimeters, techniques have been developed to overcome some of the problems of extraneous reflections ${ }^{3,4}$. However, the altimeter on the recently launched Sentinel3A has two advantages over many of its predecessors: it uses delay-Doppler (or SAR) processing to achieve a much smaller footprint and it has an extensive on-board database of expected sea surface elevations. This second aspect, i.e. the use of a Digital Elevation Model, improves the altimeter's ability to focus its reception window location at the range

\footnotetext{
Remote Sensing of the Ocean, Sea Ice, Coastal Waters, and Large Water Regions 2017, edited by Charles R. Bostater, Jr., Stelios P. Mertikas, Xavier Neyt, Sergey Babichenko, Proc. of SPIE Vol. 10422, 104220T · C 2017 SPIE · CCC code: 0277-786X/17/\$18 - doi: 10.1117/12.2277591
} 
anticipated for reflections from the sea surface rather than from the significantly higher land. This paper provides some initial coastal analysis of Sentinel-3A data, focussing mainly on the wave height.

SRAL, the Sentinel-3A altimeter, collects reflected waveforms roughly every $0.05 \mathrm{~s}$, with these returns corresponding to points every $350 \mathrm{~m}$ along-track. Frequently users access the $1 \mathrm{~Hz}$ values corresponding to the mean and standard deviation (S.D.) of consecutive groups of 20: (denoted by $\sigma_{\mathrm{h}}$ and $\sigma_{\mathrm{Ha}}$ for the S.D. in range and $\mathrm{H}_{\mathrm{s}}$ respectively).

\section{CONSISTENCY OF SATELLITE-DERIVED VALUES}

The steepness of the leading edge of the waveform is inversely related to the wave height, so waveforms associated with large $\mathrm{H}_{\mathrm{s}}$ values have a weaker slope. This in turn affects the accuracy with which the position of the leading edge can be determined, and thus the certainty on the sea level measurement. First of all, we look at the internal consistency of the altimeter data records, by considering the values for $\sigma_{\mathrm{h}}$ and $\sigma_{\mathrm{Hs}}$, and then move on to compare the Hs data with a model and a buoy.

In open ocean conditions, there is typically a wide range of values, as shown by the 2-D histograms (top row of Fig. 2). We note that, for both measures of uncertainty the median value increases with wave height (except for some greater uncertainty in $\sigma_{\mathrm{Ha}}$ at $\mathrm{H}_{\mathrm{s}}<1.2 \mathrm{~m}$ ).
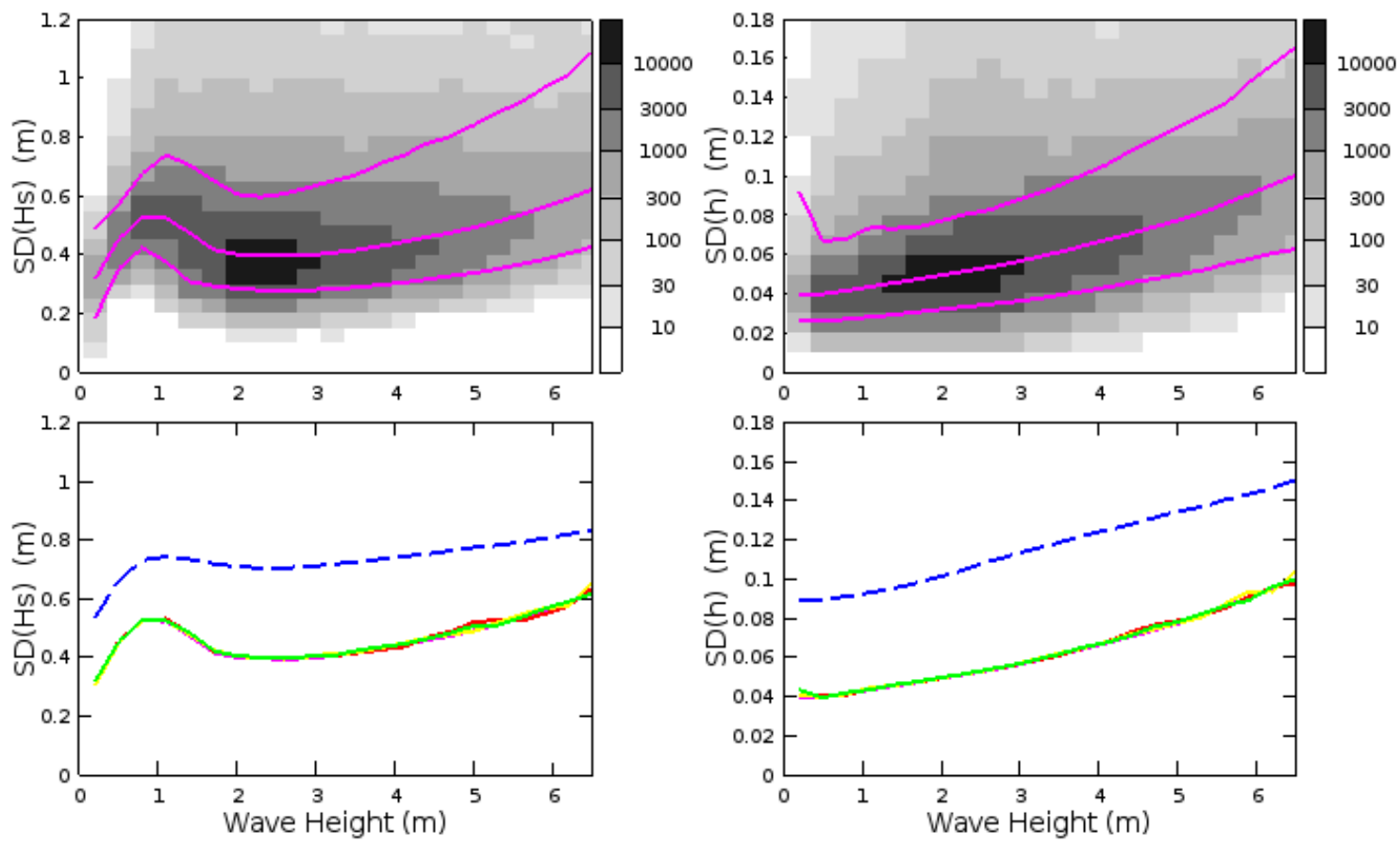

Figure 2. Measures of uncertainty in wave height $\left(\sigma_{\mathrm{Hs}}\right)$ and range $\left(\sigma_{\mathrm{h}}\right)$ as a function of $\mathrm{H}_{\mathrm{s}}$. The top row shows 2-D histograms for open ocean conditions, with the population density shown by grey shading (using a logarithmic scale) and the magenta lines indicating the 5th, 50th and 95th percentiles in each narrow $\mathrm{H}_{\mathrm{s}}$ bin. The bottom row shows how the median values increase as the coast is approached, with the solid lines for $>25 \mathrm{~km} ; 11-13 \mathrm{~km}, 7-9 \mathrm{~km}$ and $3-5 \mathrm{~km}$ being indistinguishable). For comparison, the uncertainty estimates obtained from the Pseudo-LRM (PLRM) processing for $>25$ $\mathrm{km}$ from the coast are shown by the blue dashed lines.

These $\sigma_{\mathrm{Hs}}$ and $\sigma_{\mathrm{h}}$ values are measures of the apparent short-scale variability in $\mathrm{H}_{\mathrm{s}}$ and range, and so may contain some genuine change in the parameters within the $7 \mathrm{~km}$ traversed in $1 \mathrm{~s}$, but it is likely that they principally indicate measurement error. For open ocean conditions the uncertainty in SAR mode is only $\sim 60 \%$ of that noted for PLRM for $\mathrm{H}_{\mathrm{s}}$ and only $\sim 50 \%$ for range (see bottom row of Fig. 2). The performance for SAR mode does not appear to degrade even for observations only a few $\mathrm{km}$ from the coast. 


\subsection{A focus on southwestern UK}

As a precursor to future work, we explore the typical values for $\sigma_{\mathrm{Hs}}$ in the coastal zone around the southwestern UK, by collating data from eleven of Sentinel-3A's 27-day repeat cycles. Of course, as different tracks were sampled on different days, some of this variability may be related to varying amounts of swell and locally-generated waves; however the geographical plot of typical (median) values (Fig. 3) does show increased uncertainty near the coast (especially to the north of Cornwall). Increased values of $\sigma_{\mathrm{Hs}}$ are noted for some locations close to land, but are unaffected for others.
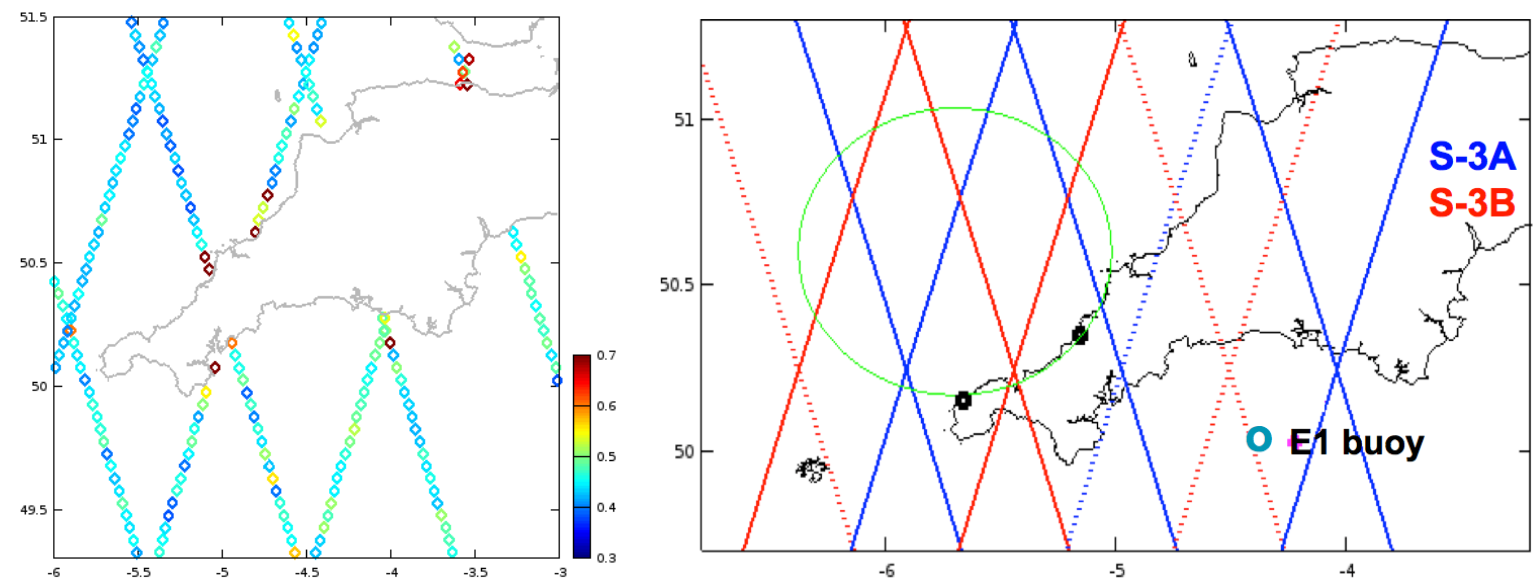

Figure 3. (left) Map of mean values of $\sigma_{\mathrm{Hs}}$ (in metres) around southwestern UK. (right) Larger view showing sampling pattern of both Sentinel-3A and Sentinel-3B (due for launch in 2018), and indicating the location of the E1 buoy (within the Western Channel Observatory) and the approximate region of coverage by the Cornish HF radar system (shown by the green circle)

\subsection{A focus on the South China Sea}

A very different set of conditions is provided by the South China Sea, a shallow well-enclosed water body so large swell or significant wind-seas are unlikely. Here we focus on a particular Sentinel-3A track traversing Vietnam and the waters
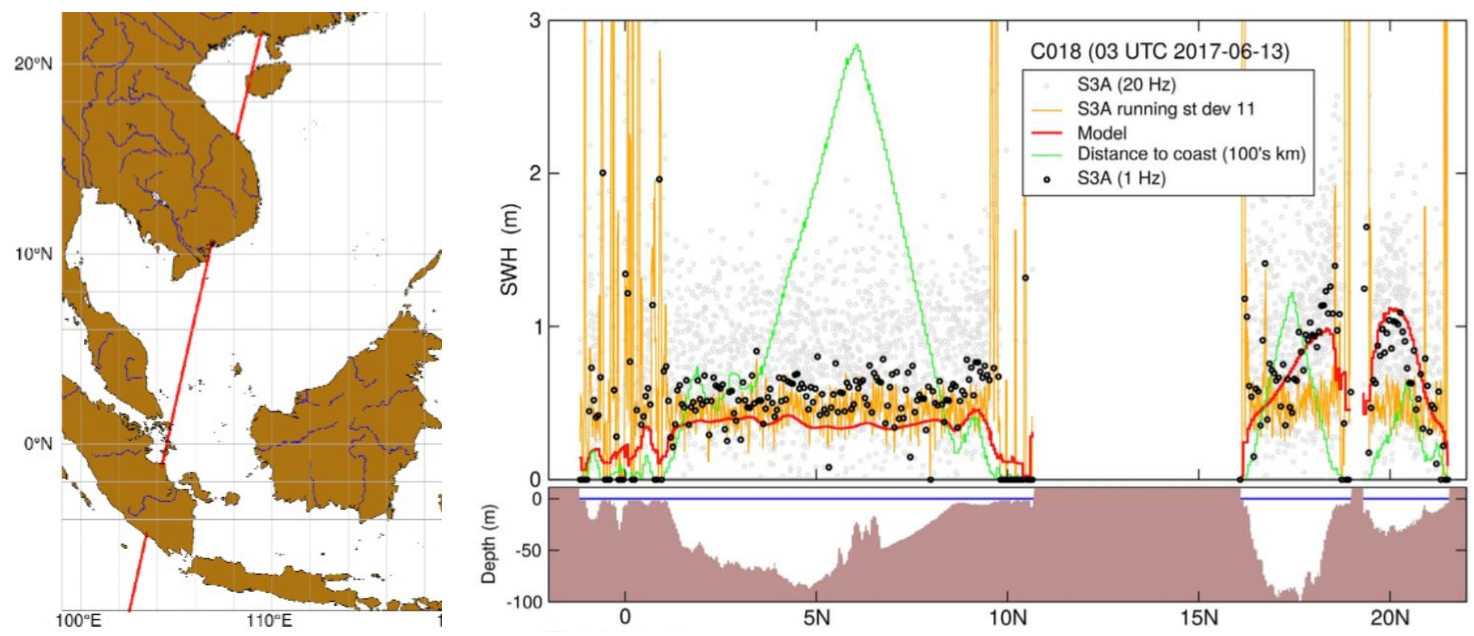

Figure 4. (left) Map of western part of South China Sea, with red line marking the descending track crossing Hainan island at $19^{\circ} \mathrm{N}$, then Vietnam $\left(11^{\circ}-16^{\circ} \mathrm{N}\right)$ then passing just east of Singapore at $1^{\circ} \mathrm{N}$. (right) Example high-frequency wave data from S-3A during cycle 018 , with bathymetry shown below. 
offshore of the Mekong delta (see Fig. 4a). To explore the errors in $\mathrm{H}_{\mathrm{s}}$ in this region, we look at two measures: a local value for $\sigma_{\mathrm{Ha}}$ and a comparison with a wave model (shown in red). The variant of $\sigma_{\mathrm{Ha}}$ is calculated using a S.D. moving window applied to 11 consecutive points (rather than adjacent separate blocks of 20); the smaller window width allows useful values to be determined closer to the coast. The wave model used for comparison is WAM constructed on a $\sim 5 \mathrm{~km}$ grid and forced by winds from the ECMWF operational analysis. For the case shown in Fig. 4 (cycle 018), the model produces lower values than the altimeter for the southern section, but the two roughly agree for the northern part

In Fig. 5 we show how the local measure of $\sigma_{\mathrm{Ha}}$ and the absolute error with respect to the model vary with the distance from coast. Only three cycles have been analysed so far for this region, and cycle 016 gave spurious values, so only cycles 017 and 018 are shown. Therefore these results are not fully robust, but both measures show greater uncertainty or error within $10 \mathrm{~km}$ of the coast, and fairly uniform performance beyond that.
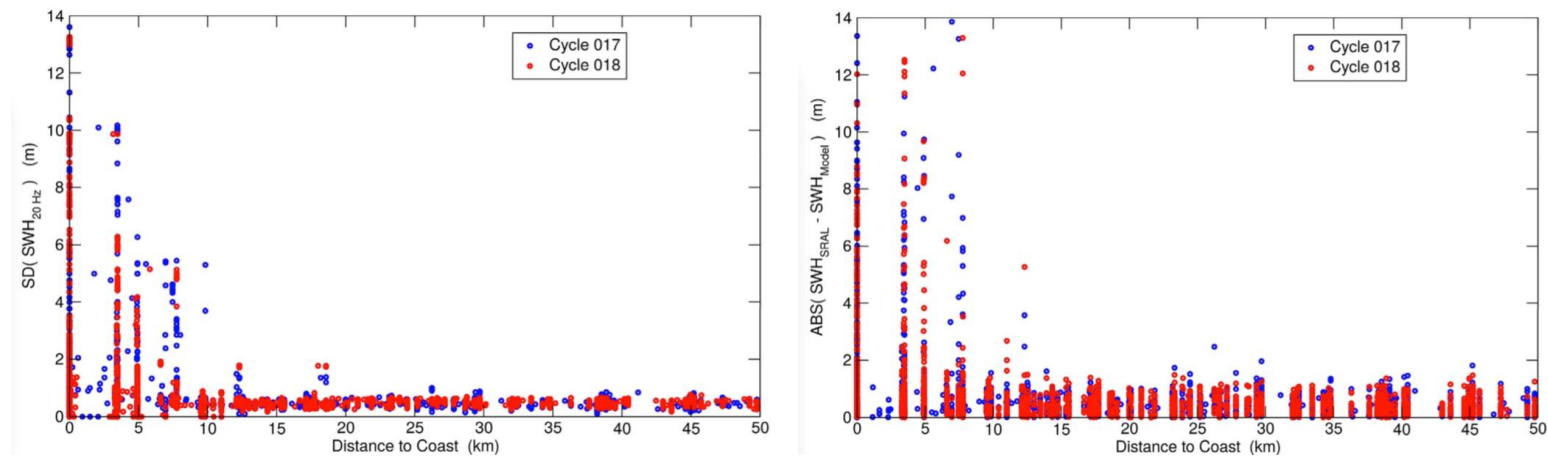

Figure 5. Variation of wave height error as a function of distance from the coast. a) Measure of altimeter uncertainty, $\sigma_{\mathrm{Hs}}$. b) Comparison with a realistic wave model. Data are for just one transect over South China Sea, with blue dots for cycle 017 and red for cycle 018 .

\section{WAVE HEIGHT VALIDATION AROUND SOUTHWESTERN UK}

The previous section mainly focussed on the internal consistency of the $\mathrm{H}_{\mathrm{s}}$ estimates produced by the altimeter, but a low value of $\sigma_{\mathrm{Ha}}$ is not in itself an indicator that the derived values are accurate. In this section we explore two approaches to quantifying bias and accuracy using two facilities in the southwest of the UK.

\subsection{Western Channel Observatory}

The Western Channel Observatory (WCO) is a location just south of Plymouth that has a history of in situ measurements (both physical and biological) dating back over a century. More recently it has been equipped with a meteorological buoy recording wave height, wind speed and other key meteorological parameters. Summary statistics are produced on an hourly basis and transmitted to the shore. The location (E1 on Fig. 3b) is not close to a particular S-3A track, but as the buoy is in an exposed location, with the swell predominantly from the west, there should be a high correlation in the wave conditions at sites $\sim 50 \mathrm{~km}$ apart.

For the two tracks indicated, we consider each satellite overflight (once every 27 days) and select the $20 \mathrm{~Hz}$ altimeter data within $75 \mathrm{~km}$ of E1. For the buoy we extract the mean wave height and the peak wave height for each of the 5 hourly samples nearest in time. These range of values (many spatial samples for the altimeter, and several hourly samples for the buoy) are indicated by the extent of the coloured lines in Fig. 6, with their intersection corresponding to the mean value. The peak values recorded by the buoy are typically $70-100 \%$ greater than the mean value; it is the latter that is most meaningful for comparison with the spatial average provided by the satellite.

These data correspond to the 11 repeat cycles in the latest reprocessing (June 2017) and show that the coincident observations lie close to the 1:1 line for track 415 (Fig. 6b), but are biased a little high for track 256 (Fig. 6a), which is further to the west. Thus this difference in behaviour may reflect a slight diminishing of wave height as the wave field progresses along the English Channel. We may therefore hope for even better agreement when S-3B is launched and in its operational phase, as one of its tracks lies very close to the E1 buoy (see Fig. 3b). 

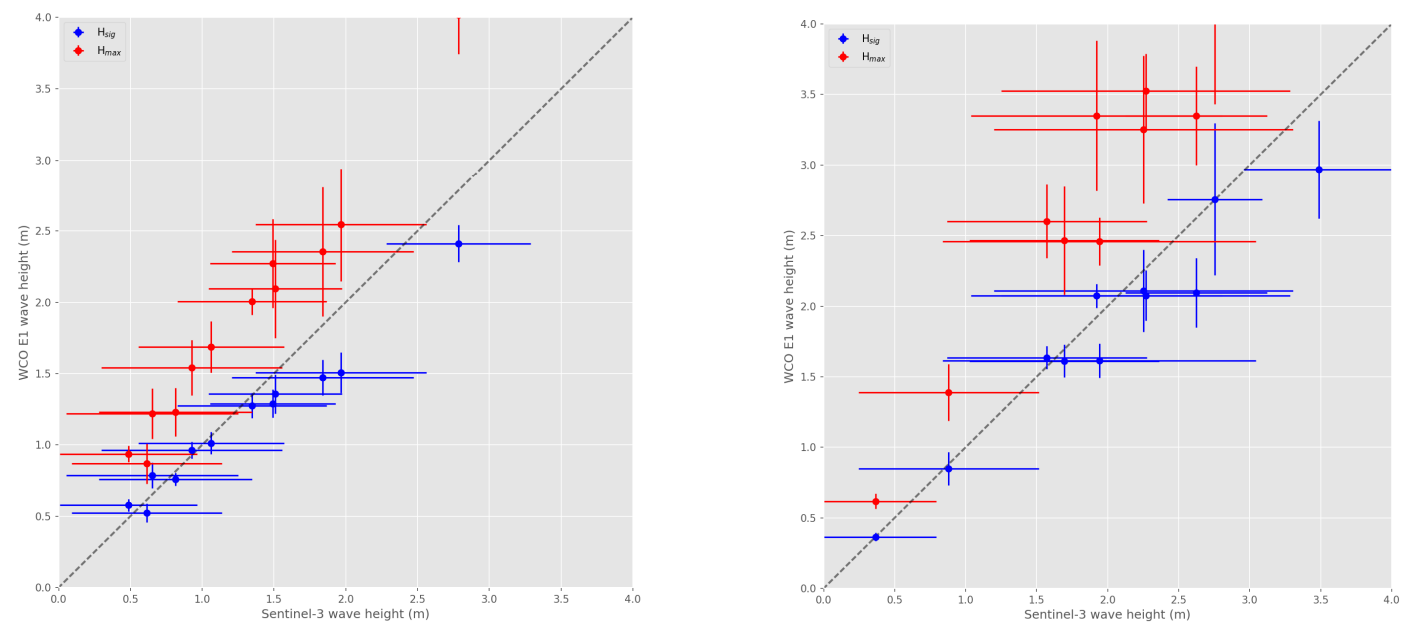

Figure 6. Comparison of data from S-3A (x-axis) with meteorological buoy. (left) Orbit 128, (track 256) which passes $36 \mathrm{~km}$ to west of buoy (Right) Orbit 208 (track 415), which passes $15 \mathrm{~km}$ to the east of the buoy. Altimeter data are the $20 \mathrm{~Hz}$ records within $45 \mathrm{~km}$ of the buoy, and buoy data are the 5 nearest hourly values to the time of the overpass, with mean SWH in blue and maximum wave height in red.

\subsection{Cornish HF Radar System}

Our second validation site is the area within regular HF radar coverage. HF radar are primarily installed to record 2dimensional surface currents from the Doppler shifts in radar reflection from 2 sites; however, with careful processing the wave field can also be estimated. This is particularly exciting because, rather than providing a single point of

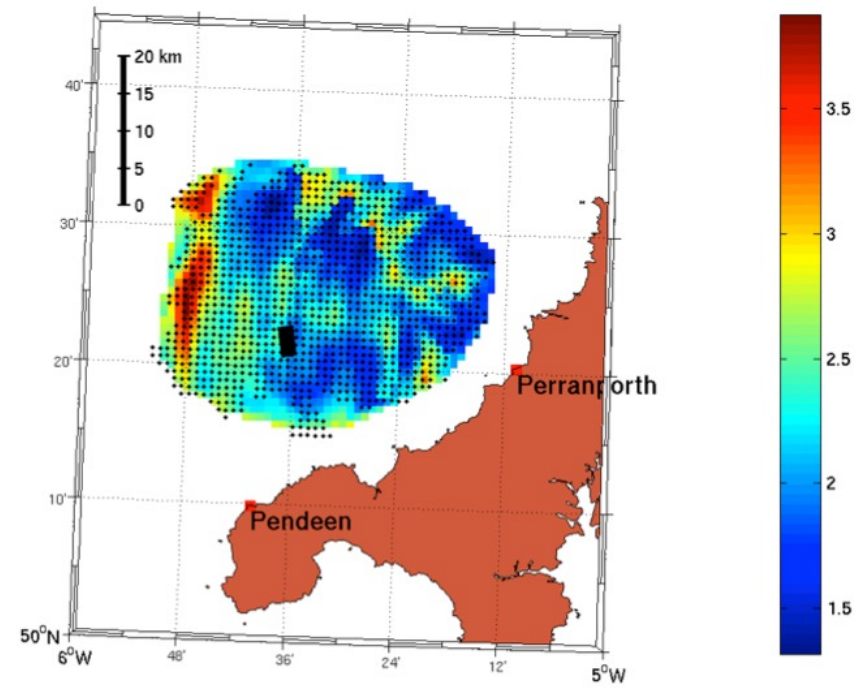

Figure 7. Illustration of the size of the region for which wave field information may be retrieved from the HF radar system. The data shown are for 16 May 2012, which is prior to S-3A's launch. 
comparison as for wave buoys, it can provide validation information on the wave field for a section of each altimeter track through the region. The particular site of interest is to the northwest of Cornwall, which is surveyed by two 16elemnt arrays (at Pendeen and Perrenporth). The wave data from this site have been previously assessed using a wave buoy, with the wave heights having a correlation of 0.95 , with an r.m.s. error of $0.3 \mathrm{~m}$, and the wave period having a correlation of 0.81 , with an r.m.s. error of $0.7 \mathrm{~s}$. This is work that is still in its infancy, so there are no results specific to S-3A overflights.

\section{SUMMARY AND FUTURE WORK}

Delay-Doppler (SAR processing) technology is designed to give radar altimeters a narrower along-track footprint and better signal-to-noise performance. The new processing (first demonstrated with Cryosat-2, launched in 2010) does show improved consistency compared with LRM instruments: the $\sigma_{\mathrm{Ha}}$ and $\sigma_{\mathrm{h}}$ values, being measures of the variability in wave height and range within twenty independent closely-spaced estimates, is significantly reduced (see bottom row of Fig. 3). However, the assessment as to whether there are biases in the altimeter algorithms, or some dependence on the mix of swell and wind sea, is more challenging to investigate, requiring a large number of validation points. Other work ${ }^{5}$, examining the accuracy of Sentinel-3A wave height retrievals over the open ocean have used a large number of buoys, ships and offshore platforms, allowing robust conclusions. Assessment as to whether S-3A delivers the anticipated improved performance in the coastal zone is challenging because of the smaller quantity of validation data.

Our initial work, with the wave data from the Western Channel Observatory, has provided 20 comparisons in the space of a year. However, these early results show a good agreement (Fig. 5). We hope that comparisons with the HF radar system will be fruitful, and allow some assessment of the spatial variations in the wave field approaching the coast. An important factor in deriving a robust assessment is that all the satellite data have been processed consistently. The data used here are from the June 2017 reprocessing (spanning the period June 2016 to April 2017), but already a further reprocessing is planned implementing SAMOSA 2.5 for the SAR processing. Therefore much of the effort so far has been in the development of methods of validation in preparation for a subsequent processing.

\section{ACKNOWLEDGEMENTS}

This work was supported by the European Space Agency through the Sentinel-3 Mission Performance Centre (S3MPC) project led by ACRI-ST.

\section{REFERENCES}

[1] Gómez-Enrí, J., Vignudelli, S., Quartly, G.D., Gommenginger, C.P., Cipollini, P,. Challenor, P. and Benveniste, J., "Modeling Envisat RA-2 waveforms in the coastal zone: Case-study of calm water contamination", IEEE Geosci. Rem. Sensing Lett., 7 (3), 474-478 (2010). doi: 10.1109/LGRS.2009.2039193

[2] Cipollini, P., Calafat, F.M., Jevrejeva, S., Melet, A., and Prandi, P., "Monitoring sea level in the coastal zone with coastal altimetry and tide gauges". Surv. Geophys, 38 (1). 33-57 (2017). doi: 10.1007/s10712-016-9392-0

[3] Halimi, A., Mailhes, C., Tourneret, J.-Y., Thibaut, P., and. Boy, F. "Parameter estimation for peaky altimetric waveforms", IEEE Trans. Geosci. Remote Sens., 51 (3), 1568-1577, (2013).

[4] Passaro, M., Cipollini, P., Vignudelli, S., Quartly, G.D., and Snaith, H.M., "ALES: A multi-mission adaptive subwaveform retracker for coastal and open ocean altimetry", Rem. Sens. Env., 145, 173-189 (2014). doi: 10.1016/j.rse.2014.02.008

[5] Quartly, G.D., and co-authors, "Ensuring that the Sentinel-3A altimeter provides climate-quality data" (art. no. 10422-30 in this Proceedings) (2017). 